\title{
artículos
}

\section{Rarezas iconográficas: San Dimas Glorioso, un ladrón poco conocido}

\author{
Rubén Sánchez Guzmán \\ Investigador vinculado a la UMA
}

\section{RESUMEN}

La desamortización de Mendizábal, supuso la destrucción, y en el mejor de los casos, la dispersión de gran parte del patrimonio escultórico que hasta este momento guardaban los conventos madrileños. En este trabajo se estudiará la imagen del Buen Ladrón de la parroquia de la Encarnación de Bailén (Jaén), muy valorada en el ámbito local, pero poco conocida fuera de sus límites geográficos. Se planteará su identificación con la que perteneció al convento madrileño de la Merced Calzada, obra del escultor toledano afincado en Madrid Juan Pascual de Mena (1707-1784). Igualmente, se intentara reconstruir en lo posible el itinerario realizado desde Madrid hasta su llegada a Bailén.

PALABRAS CLAVE: San Dimas/ Buen Ladrón/ Juan Pascual de Mena/ Bailén/ Madrid/ Museo de la Trinidad/ Merced Calzada.

\section{Strange iconographies: Saint Dimas in Glory, a little known thief}

\section{ABSTRACT}

The consequences of the disentailment of Mendizábal meant the destruction and in the best possible case, the dispersion of a great part of the artistic sculptural heritage that, until now, had been kept in monasteries and convents in Madrid. In this paper, we will look at the image of the "Good thief" in the Incarnation church of Bailén in Jaén-highly valuated localy, but otherwise lesser known further afield. We will consider its identification with that which belonged to the Merced Calzada convent in Madrid, an art work of the Toledo-born sculptor Juan Pascual de Mena (1707-1784) who later settled in Madrid. We will also try to reconstruct, if and where possible, the route the sculpture took from Madrid to Bailén.

KEY WORDS: Saint Dimas/ The Good Thief/ Juan Pascual de Mena/ Bailén/ Madrid/ Trinity Museum/ Order of Calceate Mercy.

UN LADRÓN VIAJERO EN BUSCA DE PARTENIDAD.

En la parroquia de Nuestra Señora de la Encarnación de Bailén (Jaén) se conserva en el testero de la nave de la epístola, en una capilla hornacina, una imagen del Buen Ladrón, San Dimas. La imagen llegaría a Bailén entre 1831 y 1849, fechas donde se levantaron sendos inventarios de los bienes de la parroquia coincidiendo con la entrega de la misma a un nuevo prior. Mientras en el primero no figura imagen alguna de San Dimas, en el segundo ya quedó recogida con el número 126, como llegada de

* SÁNCHEZ GUZMÁN, Rubén: "Rarezas iconográficas: San Dimas Glorioso, un ladrón poco conocido", en Boletín de Arte $\mathrm{n}^{\circ}$ 32-33, Departamento de Historia del Arte, Universidad de Málaga, 2011-2012, págs. 613-629. Fecha de recepción: Febrero de 2011. 


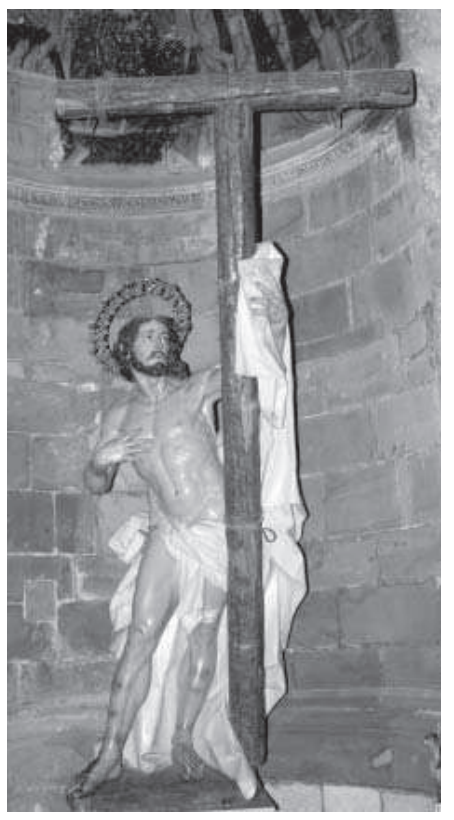

1. Juan Pascual de Mena. Atribución. San Dimas. Iglesia Parroquial de la Encarnación. Bailén.
Madrid por mediación del Duque de Osuna1.

La talla de contrastada calidad e imponente presencia, mide 2,62 metros de alto por 1,10 de ancho, representa al Buen Ladrón que fue crucificado junto a Cristo en el Calvario, en su paso triunfal hacia la Gloria eterna que le había prometido desde la cruz con su "hoy estarás conmigo en el Paraíso" (Lc 23,43) Se presenta erguido en acusado contraposto, llevando el peso del cuerpo hacia la pierna izquierda, imprimiéndole un marcado giro hacia la izquierda haciendo que los músculos se tensen, marcando una perfecta y estudiada anatomía. Se ve acompañado de la cruz conmisa donde fue crucificado que ase firmemente con su mano izquierda, mientras la contraria la dirige al pecho, en un gesto de entrega y arrepentimiento. Su juvenil y expresivo rostro barbado queda enmarcado por una movida cabellera trabajada en largos mechones. El perizona queda recogido a la altura de la cadera derecha con un cordel, no entorpeciendo por tanto la contemplación anatómica del cuerpo, mientras un blanco sudario enmarca la imagen por la espalda.

La imagen con los traslados ha sufrido bastante - ya en Bailén fue ocultada durante la Guerra Civil en el desván del colegio² - apareciendo grietas en la estructura, levantamiento de la policromía, y depósitos de suciedad en toda la superficie, quedando todo ello subsanado en la restauración a la que ha sido sometida recientemente, siendo óptima la conservación actual.

La descontextualización que ha sufrido, unida a la ausencia de datos que den más luz sobre su procedencia ha ocasionado que se hayan sucedido las atribuciones, desde la insostenible a Alonso $\mathrm{Cano}^{3}$, hasta la que nos habla de una procedencia napolitana ${ }^{4}$, pasando por la de un discípulo anónimo de Martínez Montañés ${ }^{5}$, que han chocado con

1 El inventario de 1849 fue redactado por el sacerdote de Bailén don Juan Merino y el Vice Prior Juan Ildefonso Herrera al hacer entrega de la parroquia a don Juan Pérez Galindo. Lamentablemente estos exiguos datos son los únicos con los que contamos, ya que el archivo parroquial desapareció durante la Guerra Civil. CABAZAN. Alfredo. "La Bella escultura de San Dimas". Don Lope de Sosa. № 174. Año XV. Jaén 1927a. pp. 186-187. y CABAZAN. Alfredo. "La Bella escultura de San Dimas". Andalucía. Revista regional. Córdoba, 1927b. pp. $22-23$

2 NAVÍO NAVÍO. Gaspar. Recuerdos de mi parroquia. Bailén, A. Elorza, 2002. p. 15.

3 CABAZAN. Alfredo. Op. cit. 1927a. pp. 186-187. CABAZAN. Alfredo. Op. cit. 1927b. pp. 22-23.

4 MORENO MENDOZA. Arsenio, ALMANSA MORENO, José Manuel y JODAR MENA, Manuel. Guía artística de Jaén y su provincia. Jaén, Diputación provincial de Jaén/ Fundación José Manuel Lara, 2005. p. 256.

5 ESTEVE CASTRO. Francisca. En la Tierra del Santo Rostro. Jaén, Servicio de Publicaciones de la obra 
la ausencia de un marco artístico donde poder encuadrarla satisfactoriamente. Resulta sorprendente que ninguna de ellas haya valorado la posibilidad de que la imagen haya salido de un obrador madrileño tal como consta en el citado inventario parroquial de 1849. Los estilemas de la imagen encajarían perfectamente con el modo de hacer de la escultura cortesana de mediados del siglo XVIII, en una época de transición entre la tradicional práctica gremial y la recién fundada Academia de Bellas Artes de San Fernando, momento en el que el lenguaje más barroco había sido dulcificado por cierto aire rococó de tradición europea -francesa e italiana -, que empezaba a ser atemperado por un manifiesto academicismo clasicista impuesto desde la Academia, y que se colocara, no tardando, en el umbral del Neoclasicismo. Dentro de la nutrida nómina de escultores que trabajaron

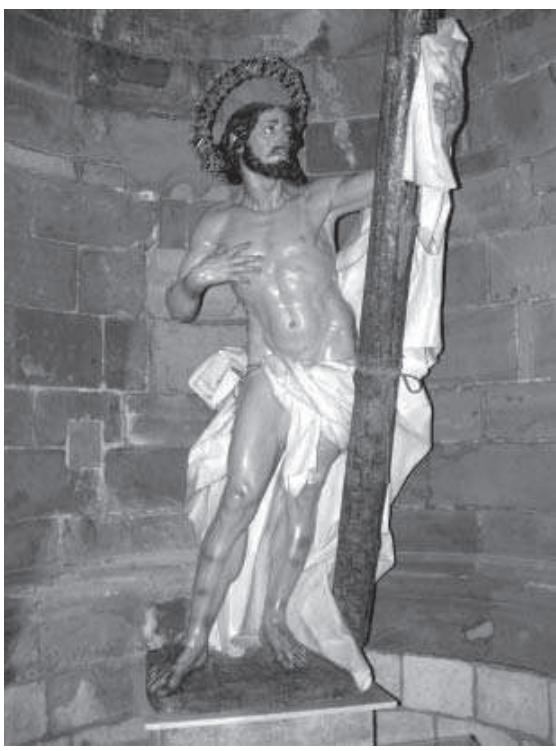

2. Juan Pascual de Mena. Atribución. San Dimas. Iglesia Parroquial de la Encarnación. Bailén. por estas fechas en Madrid, quien mejor encarnaría este proceso de cambio sería sin duda el toledano Juan Pascual de Mena (Villaseca de la Sagra (Toledo) 1707 - Madrid 1784) ${ }^{6}$ a quien cabría poner en relación con la imagen bailenense.

Para avalar tal hipótesis, analizando detenidamente la imagen del Buen Ladrón, encontramos suficientes paralelismos con la obra documentadas y de segura atribución del escultor toledano.

Su rostro joven de expresión dulce, de boca entreabierta y mirada anhelante

social y cultural de Caja Sur, 2000. pp. 340-241.

6 La bibliografía sobre el escultor es muy abundante: CEÁN BERMÚDEZ. Juan Agustín. Diccionario histórico de los más ilustres Profesores de las Bellas Artes en España. Madrid, Imprenta de la Viuda de Ibarra, 1800. Tomo III, pp. 105-108; SÁNCHEZ CANTÓN. Francisco Javier. Escultura y pintura del siglo XVIII. Ars Hispanie. Madrid, Ediciones Plus Ultra, 1958. p. 260; NICOLAU CASTRO. Juan."Esculturas del siglo XVIII en la Iglesia de San Antón de Bilbao". Estudios Vizcaínos. Nos 9-10, Año V. Bilbao. Real Sociedad Vascongada de los Amigos del País, 1974. pp. 177-192; DÍAZ FERNÁNDEZ. Antonio José. "Notas para la biografía del escultor Juan Pascual de Mena". Boletín del Seminario de Estudios de Arte y Arqueología, Tomo LII, Valladolid, 1986. pp. 501-508; NICOLAU CASTRO. Juan. "Aportaciones a la obra de Luis Salvador Carmona y Juan Pascual de Mena". Boletín del Seminario de Estudios de Arte y Arqueología, Tomo LIV, Valladolid, 1988. pp. 466-478; NICOLAU CASTRO. Juan. "El escultor Juan Pascual de Mena" Goya, No 214. Madrid, 1990, pp. 194-204; MARTÍN González. Juan José. Escultura Barroca en España. 1600-1770. Madrid, Manuales de Arte Cátedra 1991. pp.390-393; PÉREZ DE DOMINGO. Lorenzo. El Escultor Juan Pascual de Mena en Madrid. Madrid. Fundación Universitaria Española. 2007 y RAMÍREZ MARTíNEZ. José "Manuel. Juan Pascual de Mena en San Millán de la Cogolla". Kalakoricos. N II, 1997, pp. 301-307. 


\begin{tabular}{|c|c|}
\hline 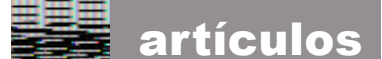 & Rubén Sánchez Guzmán \\
\hline
\end{tabular}

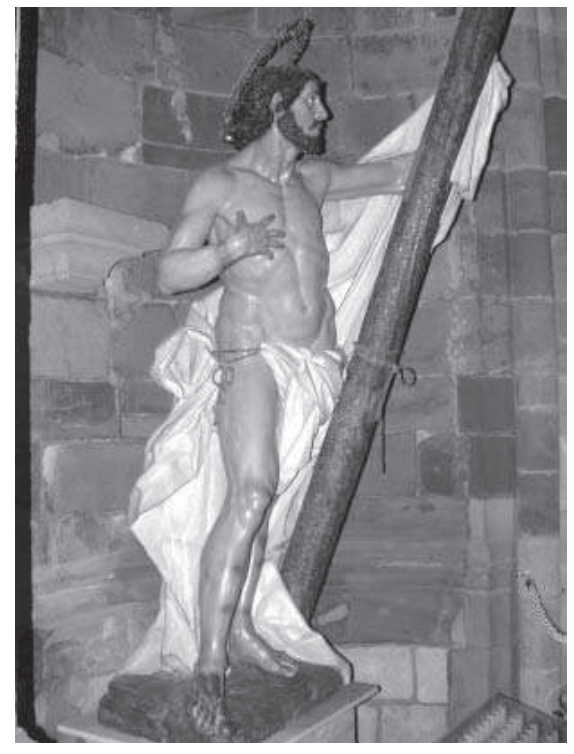

3. Juan Pascual de Mena. Atribución. San Dimas. Iglesia Parroquial de la Encarnación. Bailén.

dirigida a la cruz, le confiere cierta belleza ideal propia de sus fisonomías. El cabello que parece florar en el aire mecido por el viento, recuérdese el San Marcos de su iglesia madrileña e incluso el San Nicolás de Bilbao, la factura de la barba - no muy larga el incipiente bigote, similar al trazado en el San Crispiniano de Bilbao, pero sobre todo el San Crispín con el que se empareja, nos pone en contacto con la obra más personal del escultor.

$\mathrm{Si}$ bien es cierto que esta imagen de San Dimas parece condensar las lecciones aprendidas por Mena del clasicismo de Felipe de Castro; la marcada gesticulación en manos y pies, el verismo de venas y músculos así como la flexibilidad de los contornos, que favorece la ruptura de una visión frontal, otorga a la imagen un dinamismo y una agilidad muy marcada, propia de la imaginería tradicional. Igualmente ese poso de casticismo queda subrayado gracias a la policromía; que aunque usa de colores planos, típicos del clasicismo y recurso por el cual las esculturas de Mena parecen respirar cierto aire de familia, no se descarta en absoluto como valor expresivo al destacar las cicatrices del crurifragium ${ }^{7}$ en las piernas o las señales amoratadas que le habían dejado las sogas que le asían al madero en muñecas y tobillos ${ }^{8}$.

Los característicos pliegues del toledano, amplios y aristados, quedan visibles en el sudario que queda anudado en la cadera derecha mediante un cordel, formando un abultado pliegue, recurso este ultimo, relativamente frecuente en el recetario del

7 Castigo que consistía en quebrar las piernas del condenado con una vara de hierro o maza. "Los judíos, como era el día de la Preparación, para que no quedasen los cuerpos en la cruz el sábado - porque aquel sábado era muy solemne - rogaron a Pilato que les quebraran las piernas y los retiraran. Fueron, pues, los soldados y quebraron las piernas del primero y del otro crucificado con él. Pero al llegar a Jesús, como lo vieron ya muerto, no le quebraron las piernas" (Lc 23,49; Jn 19,31-34)

8 Para diferenciarse claramente con la figura de Cristo, una tradición medieval hacia representar a San Dimas, no clavado, sino asido a la cruz mediante sogas. Tal representación se intento enmendar a partir de la Contrarreforma, véase INTERIAN DE AYALA. Juan. El pintor Christiano y Erudito. (1730) Madrid, por Don Joachim Ibarra, 1782, p.436. Sin embargo la libertad dada a los artista para seguir una u otra iconografía, hace que Mena se ciña a la tradición más antigua y no haya considerado las cicatrices de los clavos en pies y manos, y sí las dejadas con las sogas en tobillos y muñecas. Algo similar ocurrió con la tradicional cruz en forma de T de San Dimas, que si bien fue también rebatida, se siguió usando como atributo característico del Buen Ladrón. INTERIAN DE AYALA. Juan. Op. cit. pp. 434-435. 
escultor, sirvamos como ejemplo la similar forma de quedar recogida la capa pluvial del San Blas de Bilbao bajo su brazo izquierdo.

El perfecto estudio anatómico, compartido con otras obras como el San Sebastián o el Cristo del grupo de la Piedad de las iglesias bilbaínas de San Antón y San Nicolás respectivamente, es una síntesis perfecta entre el estudio del natural y el concepto de lo clásico que disfrutaba la escultura en la Academia a estas alturas de siglo, donde convivían en armonía distintas influencias que iban desde la estatuaria antigua hasta la que procedía directamente de los escultores del renacimiento y barroco, como Miguel Ángel, Bernini o el "Flamenco" François Duquesnoy", pasando por obras contemporáneas de los mismos profesores de la academia que habían sigo consideradas dignas

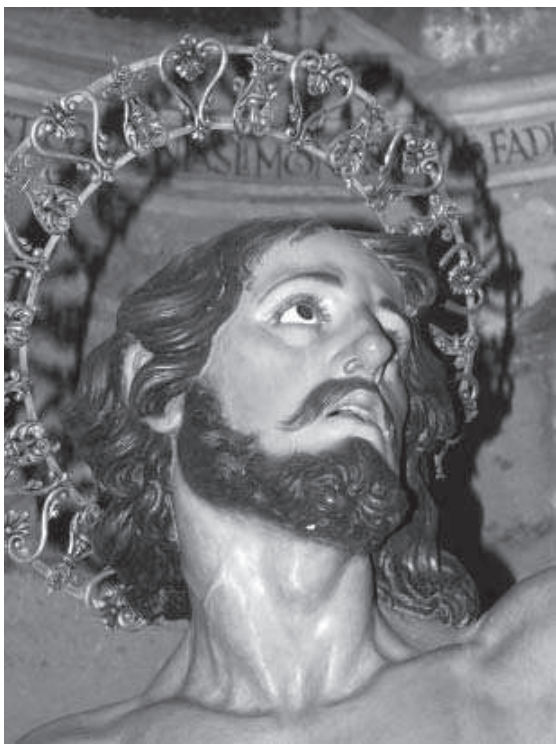

4. Juan Pascual de Mena. Atribución. San Dimas. Detalle del rostro. Iglesia Parroquial de la Encarnación. Bailén. para el estudio ${ }^{10}$. No cabe duda que Mena estaba perfectamente familiarizado con la estatuaria clásica, recordemos que fue el encargado de reparar los vaciados que había traído Velázquez de Italia que no habían perecido en el incendio del Alcázar. En efecto, los ecos del Laocoonte, del gladiador Borghese, del Hércules Farnese o del Sileno con Baco del Vaticano, vaciados que el mismo restauró ${ }^{11}$, se hacen presentes en la obra, que constituye una especie de ensayo general para el Neptuno del Paseo del Prado, que le colocará decididamente en el umbral del Neoclasicismo. Justamente la abultada musculatura del Dios, que le ocasionó a Mena algunas críticas en el siglo $\mathrm{XIX}^{12}$, queda perfectamente apuntada en la imagen de Bailén.

No obstante, también es visible la presencia de Miguel Ángel, a través del Cristo Redentor de Santa Maria Sopra Minerva, obra muy estimada en el siglo XVIII, como fuente

9 CHOCARRO BUJANDA. Carlos. La Búsqueda de una identidad. La Escultura entre el Gremio y la Academia (1741-1833). Madrid. Fundación Universitaria Española. 2001. pp. 197-199.

10 CHOCARRO BUJANDA. Carlos. Op. cit. p. 205.

11 HERAS CASAS. Carmen. "Modelos en yeso de esculturas antiguas que Velázquez trajo de Italia en 1651", Boletín de la Real Academia de Bellas Artes de San Fernando. № 88, Primer Semestre, 1999. pp. 507-526

12 "Sus estatuas... descubren en el desnudo del empeño de ostentar más allá de lo justo es estudio de la anatomía; aparece en ellas la musculatura abultada en demasía, y se quisiera que otra combinación de las partes planas y las curvas evitase la monotonía de una escasa morbidez". CAVEDA Y NAVA. José. Memorias para la historia de la Real Academia de San Fernando y de las Bellas Artes en España. Tomo I. Madrid, Imprenta de Manuel Tello, 1867. p. 84. 


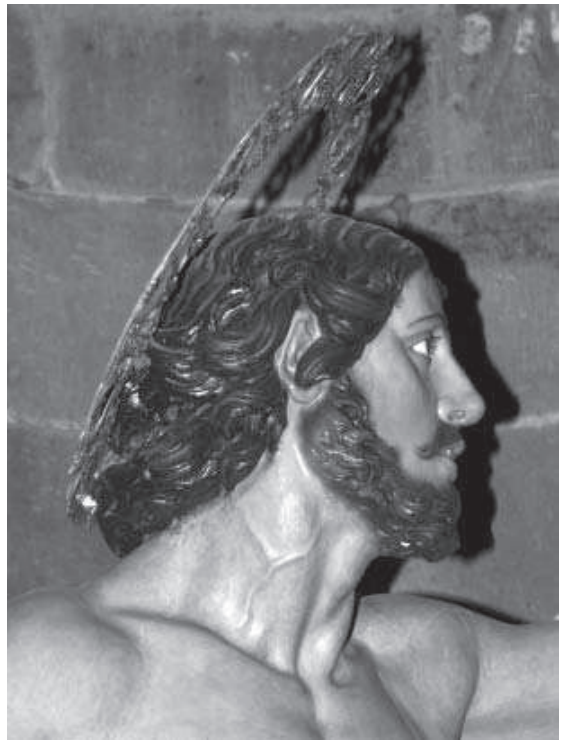

5. Juan Pascual de Mena. Atribución. San Dimas. Detalle del rostro. Iglesia Parroquial de la Encarnación. Bailén. de inspiración y que seguramente pudo conocer Mena, ya sea directamente por alguno de los muchos grabados que circulaban, desde el de Nicolás Beatrizet (1507/15 - 1573) hasta el incluido en la Paradigmata Graphices Variorum Artificum (1671) de Jan de Bisschop (1628-1671) pasando por el de Jacob Matham (1571-1631), 0 indirectamente por otras fuentes, como la imagen madrileña del Cristo de los Dolores, ideada un siglo antes por Domingo de la Rioja ${ }^{13}$, o la tabla de Rubens de Cristo y los Pecadores Arrepentidos de la Alte Pinakothek de Munich, composición que conoció varias copias y versiones ${ }^{14}$, y que tubo que conocer por algún grabado, quizá el Remilluntur ei peccata multa, que fue lanzado por Nicolás Lauwers (16001652) y posteriormente en Amberes, por Martín Van den Enden ${ }^{15}$, lo cual explicaría las similitudes fisiognómicas entre la versión del Buen Ladrón

de Bailén y su homónimo de Munich, véase el aspecto juvenil del rostro, el cabello arremolinado, o la manera de individualizar la barba rala y el bigote.

Leticia Azcue quiso identificar un busto de San Dimas entre las colecciones de la Academia de San Fernando como obra de Juan Pascual de Mena ${ }^{16}$. Tal identificación

13 Si la imagen original del Cristo de los Dolores o de la Victoria fue llevada a Serradilla (Cáceres) en 1641, esta era perfectamente conocida en la Corte por las estampas que se tiraron y las copias que se hicieron de ella. Alguna autógrafa del propio Rioja como la entregada a la Venerable Orden Tercera de San Francisco de Madrid, otras anónimas como la conservada en el templo de Los Jerónimos o la desaparecida del Convento del Rosario. SÁNCHEZ GUZMÁN. Rubén. "La imagen simbólica de la Pasión. Bussy, Rioja y Manuel Pereira", Los Coloraos. Real Archicofradía de la Sangre de Cristo, N 61, Murcia. 2009, pp. 57-58.

14 FREEDBERG. David. Corpus Rubenianum, Ludwing Burchard. Part. VII. The life of Christ after the Passion. Oxford University Press, Harvey Miller Publishers, 1984. pp 55-58.

15 Existe un posible dibujo preparatorio para este grabado en el Musée du Louvre. Inventaire du Départemet des Arts Graphiques. INV. 20225. Un ejemplar del editado por Lauwers en el Victoria \& Albert. Prints \& Drawings. DYCE, 2243. y del posterior de Van den Enden en el British Museum. Prints \& Drawings. 1981,0414,679. Acerca de los grabados, véase: Schneevoogt, C. G. Voorhelm Catalogue des estampes gravees d'apres P.P. Rubens. Harlem, Les heritiers Loosjes, 1873. p. 64; DUTUIT. Eugene. Manuel de l'amateur d'estampes (1885). Tome IV. Ámsterdam, G. W. Hissink \& Co, 1972. p. 84; ROOSES. Max. L'ouvre de P. P. Rubens (1886-1892). Second Volume. Soest-Holland, editions Davaco, 1977. pp. 204-205 y Hollstein, Dutch and Flemish etchings, engravings and woodcuts, ca. 1450-1700, Volume XX, Amsterdam, Van Gendt \& Co, 1978. p.123. No obstante a partir de la ultima década del siglo XVIII, la imagen se populariza aún más, conociéndose al menos otros tres litografías nuevas.

16 AZCUE BREA. Leticia. La escultura en la Real Academia de Bellas Artes de San Fernando. Catálogo y estudio. Madrid. Real Academia de Bellas Artes de San Fernando, 1994. pp. 212-213. 
ha sido recientemente descartada considerándolo como un ensayo para la cabeza del gladiador Borghese a la hora de preparar su restauración ${ }^{17} \mathrm{y}$ aunque es posible rastrear el estilo de Mena, no guarda ninguna relación con la imagen de Bailén.

UnA historia aJetreada. De MAdRID A Bailén.

Era imposible que una imagen de tanta presencia y singularidad no hubiera dejado rastro alguno durante su permanencia en la Corte. Hemos podido rastrear varios datos que nos permiten identificar la imagen de Bailén con la que Antonio Ponz primero ${ }^{18}$ junto con Ceán Bermúdez y los inventarios de las desamortizaciones de 1809 y 1836 después, localizaron

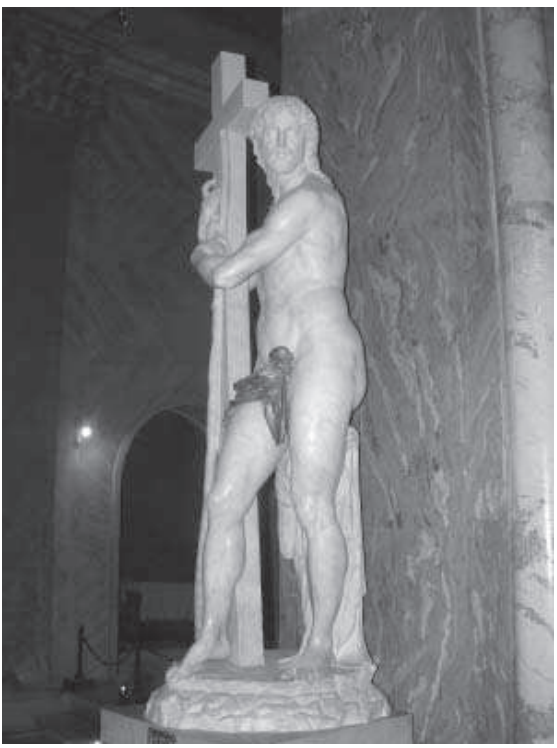

6. Miguel Ángel. Cristo Redentor. Iglesia de Santa María Sopra Minerva. Roma. en el desaparecido monasterio de la Merced Calzada de Madrid, citada como obra de Juan Pascual de Mena. Tal atribución no debe ocasionarnos dudas, ya que Ponz, conocía personalmente a Pascual de Mena y su trayectoria artística, aun más si se trataba de una obra realizada para la capital. Recordemos que en 1776, año de la publicación del tomo $\mathrm{V}$ de su Viage de España, dedicado a Madrid, donde su incluyó tal atribución, y de su toma de posesión del cargo de Secretario de la Real Academia de Bellas Artes de San Fernando, Mena acababa de terminar su mandato como Director General de la institución.

Además de las ya estudiadas analogías estilísticas con la obra de Mena, existen otros indicios que nos permiten plantear la hipótesis de que la imagen localizada en Merced saldría de la capital a partir de la desamortización de Mendizábal rumbo a Bailén.

Así, el gran tamaño de la imagen no pasó inadvertido: tanto Ponz como Ceán Bermúdez ${ }^{19}$, así como los inventarios de las desamortizaciones de 1809 y 1836 y el redactado por la apertura provisional del Museo de la Trinidad en 1838 hacen especial hincapié en su tamaño "mayor que el natural", rasgo que comparte plenamente con la

17 LUZÓN NOGUÉ, José María. (ed.). Velázquez. Esculturas para el Alcázar. Catálogo de la Exposición. Madrid. Real Academia de Bellas Artes de San Fernando, 2007. pp. 467-469 y LUZÓN NOGUÉ, José María. (ed.). Ecos de Velázquez. Catalogo de la Exposición. Murcia. Fundación Caja Murcia y Real Academia de Bellas Artes de San Fernando, 2008. pp. 45-52.

18 PONZ. Antonio. Viage de España. Tomo V. Madrid, por Don. Joachim Ibarra, 1776. p.104

19 CEÁN BERMÚDEZ. Juan Agustín. Diccionario histórico de los más ilustres Profesores de las Bellas Artes en España. Madrid, Imprenta de la Viuda de Ibarra, 1800. Tomo III, pp. 105-108 


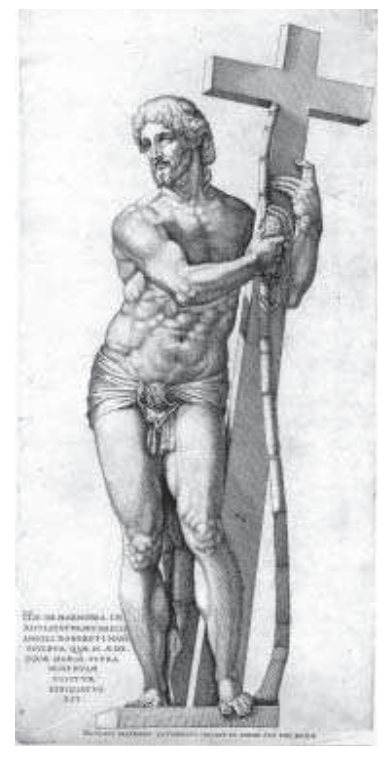

7. Nicolás Beatrizet. Cristo Redentor. Grabado después de Miguel Ángel. imagen bailenense de más de dos metros de altura.

Otro detalle importante es su singular iconografía: Ponz nos da la clave al describir a la imagen madrileña de San Dimas, como "representado glorioso"20, iconografía harto infrecuente. Ni la historiografía artística del momento - Felipe de Castro, Ponz o Ceán Bermúdez -, ni los inventarios de los conventos suprimidos, citan otra imagen de esta iconografía ni similar que pueda ocasionar duda en la capital.

En efecto, como ya apunto Louis Reau ${ }^{21}$ en su compendio sobre iconografía cristiana, las representaciones aisladas del Buen Ladrón, son escasas. A lo que cabría añadir que aquellas que le representan en su paso triunfal hacia la Gloria eterna prometida por Cristo desde la cruz, siguiendo las Actas de Pilato $^{22}$, son aun más difíciles de encontrar en el arte occidental. Sin embargo, en la tradición bizantino-ortodoxa, ya desde antiguo, su imagen aparece perfectamente codificada (desnudo, cubriéndose con paño de pureza y portando una cruz), aunque desempeñando un papel secundario, asociado iconográficamente a otros temas. Así, aparecerá siguiendo a los apócrifos, acompañando a Cristo en su descenso al limbo (Anástasis), como guardián del Paraíso, junto a Serafín y los Patriarcas o encabezando a los Bienaventurados en el Juicio Final. No obstante y aunque el Arte de Occidente bebe de estas fuentes para crear muchos de sus temas, tal es el caso de la primera aparición de cristo a la Virgen tras su Resurrección, donde suele aparecer también el Buen Ladrón, estos quedaron frenados, en mayor o menor medida, por las directrices emanadas del concilio de Trento, que expurgaron aquellas representaciones que se salían de la ortodoxia. Por lo tanto, la definitiva independencia iconográfica del Buen Ladrón también parece ser un fenómeno oriental, encontrándonos las primeras manifestaciones en fecha tardía. Sírvanos el icono conservado en el Museo del Kremlim de Moscú, de hacia 1560, donde aparece como custodio del Paraíso que adquiere la forma de un jardín.

Mientras tanto, la Contrarreforma promovía la figura del Buen Ladrón. Al Ilamar la

20 PONZ. Antonio. Op. cit. p.104.

21 REAU. Louis. Iconografía del arte cristiano. Iconografía de los Santos. De la A a la F. Barcelona, Ediciones el Serbal, 1997. pp. 378-380.

22 "Mientras estos se expresaban así, vino otro hombre de apariencia humilde, que llevaba además sobre sus hombros una cruz. Le dijeron los Santos Padres: ¿Quién eres tu, que tienes aspecto de ladrón y qué es esa cruz que llevas sobre tus hombros? Él respondió: Yo según decís, era ladrón y salteador en el mundo, y por eso me detuvieron los judíos y me entregaron a la muerte de cruz juntamente con Nuestro Señor Jesucristo". Actas de Pilato en Los evangelios Apócrifos. Madrid, Biblioteca de Autores Cristianos, 2006. p.235. 


\begin{tabular}{|c|c|}
\hline 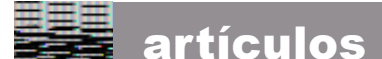 & Rarezas iconográficas: San Dimas Glorioso... \\
\hline
\end{tabular}

atención sobre su arrepentimiento en la cruz, adquiría un claro significado penitencial, yendo paralelo a la importancia dada a los Sacramentos en Trento, dando respuesta al rechazo de estos por la Reforma. Su caso se convertirá en ejemplo paradigmático de conversión in extremis, característica, que le otorgara el total protagonismo en los sermones (Martes Santo), precisamente el día en que la Iglesia hacía la última llamada al arrepentimiento de los pecados antes de asistir al Oficio de Tinieblas queabríalas celebraciones Pascuales, al siguiente día.

Esa conveniencia del uso de la figura del Buen Ladrón como ejemplificación didáctica de la conversión, fue ampliamente

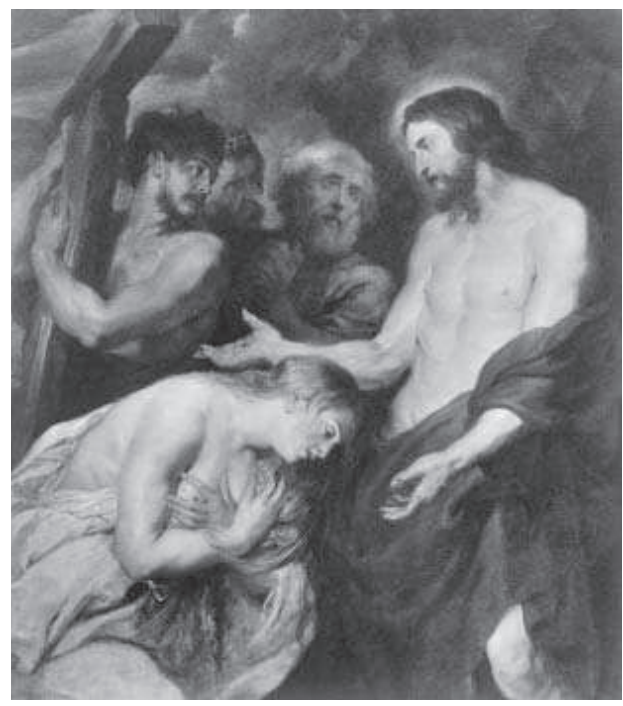

8. Peter Paul Rubens. Cristo y los pecadores arrepentidos. Alte Pinakothek. Munich. recogida por la literatura religiosa,

el Libro de la Conversión del Buen Ladrón, 1606, respondería precisamente a la necesidad de dotar a esta figura de un marco teológico adecuado para estos fines. La obra, publicada en Amberes por el franciscano recoleto Andrés de Soto ${ }^{23}$, confesor de la Infanta Gobernadora Isabel Clara Eugenia, serviría de preámbulo para la popularización de su figura entre los católicos del norte y su inclusión en el arte, junto con otros santos pecadores que habían sido redimidos por la divina misericordia, así San Dimas, además de Maria Magdalena, San Pedro, o el publicano, pero también el Rey David y el Hijo Pródigo de la parábola, se convertirá en la representación más clara del arrepentimiento, encontrándolo en actitud devota portando su cruz junto a estos, rodeando a la figura de Cristo en la tabla de Rubens (1577-1644) de la Alte Pinakothek de Munich o en lienzo de Gerard Seghers (1591-1651) del Rijksmuseum de Amstendram, a de la Virgen con el Niño, en la tela, también de Seghers, de la iglesia de San Antonio de Padua en Amberes, o junto a María intercesora ante la Santísima Trinidad, tal como los mostró Petrus Bernaerdt para la Iglesia de Nuestra Señora de Vrouw de Brujas (h. 1660). O en escultura, decorando los verdaderos templos del arrepentimiento y el consiguiente perdón: los confesionarios. Ejemplos destacados encontramos en la Iglesia de San Pablo de Ámsterdam obra de Artus

23 SOTO. Andrés. Libro de la conversión del Buen Ladrón, y declaracóon de las palabras que dixo à lesu Christo en la Cruz, y de las que por respuesta oyò de su divina boca. Amberes, casa de la biuda y herederos de Pedro Bellero, 1606. 


\begin{tabular}{|c|c|}
\hline 啡車 artículos & Rubén Sánchez Guzmán \\
\hline
\end{tabular}

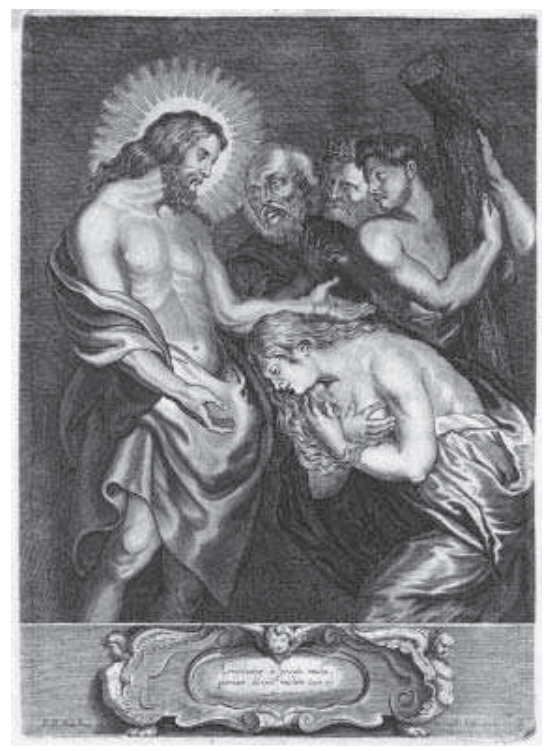

9. Martin Van den Enden. Remilluntur ei peccata multa. Grabado después de Rubens.
Quellinus II (1625-1700), otro de Egidius Adriaan Nijs (1683-1771) en la Santa Cruz de Stekene, o los cuatro dieciochescos de la colegiata alemana de Buchau, realizados en estuco por Johann Joseph Christian (1706-1777).

No obstante, esta suerte de "sacra conversación penitencial" quedó circunscrita al arte de las regiones católicas del norte y centro de Europa, por lo que será aquí donde parece adquirir, la imagen del Buen Ladrón, su independencia iconográfica. Así, la extraordinaria escultura de Franz Ignaz Günther (1725-1775) en la abadía premostratense de San Pedro y San Pablo de Freising, o los anónimos en la abadía de San Marino y San Aniano de Rott am Inn, del santuario austriaco de Maria Rehkogel o del puente de Breznice, Republica Checa, coinciden en lo esencial, al efigiarle

en pie portando su cruz y tapando su desnudez con un paño de pureza.

Mientras tanto, el Arco mediterráneo parece permanecer ajeno a estas representaciones, siendo escasa la presencia de esta iconografía gloriosa o triunfal en esta zona geográfica. En Francia se prefiere su representación como crucificado, y en Italia, si bien es cierto que encontramos ejemplos en fechas tempranas (iglesia de Santa María Imfrasporta de Foligno, siglo XII, o Iglesia de la Assunta de Torcello, siglo XIII), muestran una fuerte dependencia de los modelos bizantinos, al estar representado en el Paraíso junto a un Serafín guardián, escaseando posteriormente las representaciones que se le representa aislado. En la plástica hispana, rica en representaciones del Buen Ladrón en el calvario junto a Cristo y los demás personajes del ciclo de la Pasión, y en menor medida crucificado en solitario - el propio mercedario y tratadista madrileño Interián de Ayala en su diccionario iconográfico solo menciona esta variante ${ }^{24}$ - es cicatera con la que le representan glorificado. Resulta revelador el caso de Valencia, ciudad donde se le rendía cierto culto a San Dimas ${ }^{25}$, y que incluso llegó a conseguir en 1729 de la Congregación de Ritos fiesta y oficio propio ${ }^{26}$.

24 INTERIAN DE AYALA. Juan. Op. cit. pp.170-172.

25 MIR CUÑAT. José. "San Dimas y el donante (atribuida a Miguel Esteve) Estudio icnográfico e iconológico", Ars Longa, Número 12 Valencia, 2003, p. 35.

26 SEGURA. Jacinto. Norte critico con las reglas más ciertas para la discrecion en la historia y un tratado preliminar para instrucción de historicos principiantes. Valencia, imprenta de Joseph García, 1733. p. 314. 
De todas las manifestaciones que de él se han conservado en la ciudad levantina, tan solo una, la que aparece en la bóveda de la basílica de los Desamparados, junto con otros santos mártires glorificados, le representa de esta manera. Algo parecido ocurre en el resto del territorio hispano donde tan solo hemos podido recoger dos, ambas escultóricas y de cronología muy tardía: la que nos ocupa de Bailén, y otra en la iglesia de San Felipe Neri de Cádiz, de clara influencia genovesa ${ }^{27}$.

La misma tendencia se repite en el arte hispanoamericano, donde tan solo hemos podido localizar el lienzo de Pablo A. García en la iglesia de San Ignacio de Santa Fe de Bogotá (Colombia).

Después de este inciso y retornando a nuestra propuesta de identificación, aún podemos apuntar un último argumento para considerar ambas imágenes como la misma, un dibujo de San Dimas atribuido al pintor Vicente López guardado en la

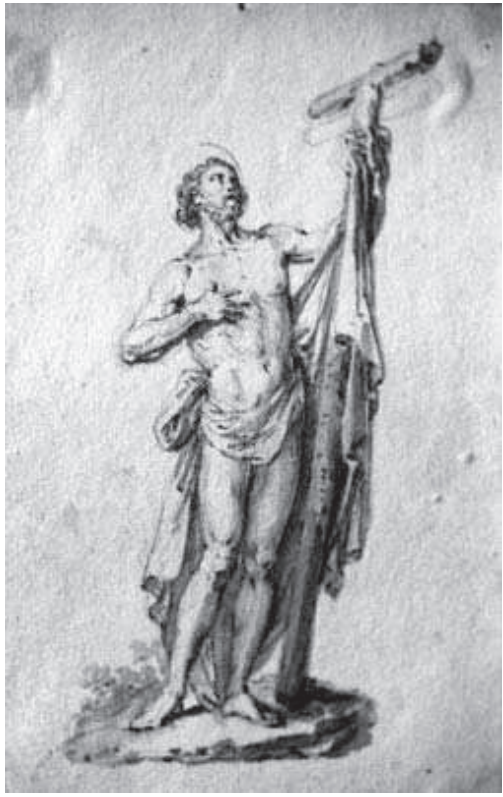

10. Vicente López. Atribución. San Dimas. Biblioteca Nacional. Madrid. Biblioteca Nacional de España ${ }^{28}$. López, aunque valenciano de nacimiento, ciudad donde desarrolló parte de su carrera, fue en Madrid donde discurrió la mayor parte de su trayectoria profesional. El parecido que encierra el dibujo con la imagen de Bailén, salvo leves variantes como el paño de pureza, es sencillamente asombroso, ya no solo en los elementos más generales, tales como la postura del cuerpo, la forma de la cruz o la disposición del sudario y su manera de recogerlo mediante un abultado pliegue a la altura de la cadera derecha, sino también en los detalles más mínimos, como la colocación de los dedos de su mano derecha, pudiéndose entender el dibujo como un apunte directo de la imagen de Bailén, antes de que esta abandonara la capital. Como ya advirtió Barcia el dibujo esta concebido como preparatorio para un grabado posterior, que bien, o no se llegó a publicar o no ha llegado hasta nosotros ${ }^{29}$.

27 SÁNCHEZ PEÑA. José Miguel. Escultura Genovesa. Artífices del setecientos en Cádiz. Cádiz, JiménezMena, 2006. p. 203.

28 BARCIA Y PAVÓN. Ángel María. Catálogo de la Colección de dibujos originales de la Biblioteca Nacional. Madrid, Tipografía de la Revista de Archivos, Bibliotecas. y Museos, 1906. p. 385. $n^{\circ}$. 3819. Actual signatura: Dib/14/20/15. La atribución ha sido mantenida recientemente por: DIEZ. José Luis. Vicente López (1772-1850). Tomo II, Madrid, Fundación de Apoyo a la Historia del Arte Hispánico, 1999. D-205. p.332. Tanto Barcia como Diez, aunque identifican el dibujo como San Dimas, lo dan como dudoso.

29 El Dibujo ha sido relacionado por José Luis Diez con otro de San Antonio de Pádua, fechable hacia 1805 Quizá haya que fijar la cronología del dibujo de San Dimas en fechas similares. 
Un viaje en el tiempo nos lleva de nuevo al convento madrileño de la Merced Calzada, donde estuvo una imagen del Buen Ladrón hasta la exclaustración firmada por Mendizábal. La imagen recibió culto en el retablo relicario que se adosaba al testero del crucero del lado del Evangelio, emparejado, frente por frente, con el sepulcro de don Fernando Cortés, nieto del Hernán Cortés y III Marqués del Valle de Oxaca, y de su esposa, doña Mencía de la Cerda $^{30}$. La construcción del relicario se viene fechando entre 1635, cuando se contratan el Sepulcro de los Marqueses ${ }^{31}$, y 1659, cuando el pintor Juan Fernández de Gandía se obligaba a decorar los testeros del crucero con unas arquitecturas fingidas que enmarcarían tanto el sepulcro de los marqueses como la "caja" de las reliquias ${ }^{32}$. En una descripción del interior de la iglesia de 1669, se nos describe, "como de finísimos jaspes... donde con gran asseo y tan nuevas y diversas reliquias, repartidas por sus urnas y en medio una imagen ricamente vestida de nuestra señora de la Merced; cerrado con dos curiosas puertas que se abren los días de gran solemnidad y cuando se celebra la fiesta del santo cuya reliquia se guarda"33. Sin embargo, y dentro del programa de redecoración integral de la capilla mayor del Convento emprendida hacia $1740^{34}$, este conjunto modificó su aspecto en 1750 bajo el segundo mandato del comendador fray Pedro de la Plaza ${ }^{35}$, describiéndolo Ponz como decorado de la misma forma (que el sepulcro de los marqueses) pero realizado en madera. Desconocemos en qué momento justo la imagen de vestir de Nuestra

30 Sobre la historia, patronato y decoración de la Capilla mayor de la Merced a principios del siglo XVII, véase: CERVERA VERA. Luis. ESTELLA. Margarita.. BLANCO MOZO, Juan Luis.

31 La obra fue contratada el 22 de octubre de 1635 al marmolista Juan Francisco Sormano. Sospecha Blanco Mozo que el escultor Pedro de Tapia, testigo del documento, participara también en su ejecución BLANCO MOZO, Juan Luis. Op. cit. p. 116 .

Los bultos funerarios de don Fernando y doña Mencía, identificados por Margarita Estella, véase ESTELLA. Margarita. Op. cit. pp. 255-260, está depositados a día de hoy en el Museo del Traje de Madrid.

32 CERVERA VERA. Luis. Op. cit. p. 358.

33 Biblioteca Nacional (B.N) Ms 2684 fol. 49. vto.

34 Así en el mandato del comentador Fray Lorenzo Hernández (1740-1742) se enlosa de mármol toda la capilla y se hace y dora el nuevo retablo mayor (B.N) Ms 2684 fol 7. vto. Se conserva un dibujo de retablo firmado por José de Churriguera que se ha identificado como proyecto para este retablo. RODRÍGUEZ G. DE CEVALLOS. Alfonso. Los Churriguera. Madrid, Instituto Diego Velázquez (C.S.I.C), 1971. p. 22. Sin embargo este proyecto no parece que se llevó a la practica en su integridad, a tenor de la gran cantidad de esculturas que se distribuían por el retablo y que no aparecen proyectadas en el dibujo. Salvo la imagen titular de Nuestra Señora de la Merced, obra de Juan Pascual de Mena. véase, PONZ. Antonio. Op. cit. p.104, el resto de esculturas fueron realizadas por Luis Salvador Carmona. El trabajo comprendía además de diez Ángeles de distintos tamaños, las imágenes de San José, San Pedro, San Pedro Nolasco, San Ramón Nonato, San Serapio, San Pedro Armengol, Santa María de Socors y otra más de Dios padre. Y para la Custodia un niño Jesús con un Cordero, una paloma del Espíritu Santo, veinte y ocho cabezas de Ángeles y cuatro Ángeles mancebos. véase A.R.A.B.S.F. Compendio de la Vida y obra de Don Luis Salvador Carmona. Año de 1775. publicado por MARTíN GONZÁLEZ. Juan José. Luis Salvador Carmona. Escultor y Académico. Madrid Alpuerto, 1991. pp. 30-31. Unos años más tarde bajo el primer mandato de Fray Pedro de la Plaza, (17461748) se acomete la reforma de los colaterales, dorándolos de nuevo (B.N) Ms 2684 fol. 7. vto. Para estos realizo Carmona sendas parejas de Ángeles. A.R.A.B.S.F. Compendio. Año de 1775. Op. cit. p. 31. En 1750 bajo el segundo mandato del comendador Fray Pedro de la Plaza se realizaron el relicario y los tornavoces de los pulpitos (B.N) Ms 2684 fol. 7. vto. Rematados por sendas tallas de los evangelistas también de Carmona. A.R.A.B.S.F. Compendio. Año de 1775. Op. cit. p. 31. Un año después (1751) se doraron las tribunas de la iglesia y los pilares de los muros. Quedando rematada la capilla mayor con la colocación de tres lámparas de plata entre 1758 y 1761 . Todas estas reformas corrieron a expensas del padre mercedario Fray Miguel Antonio Rodríguez. (B.N) Ms 2684 fol. 7. vto.

35 B.N. Ms 2684 fol. 7. vto. Fray Pedro de la Plaza. 1750. "El relicario de San Dimas se hizo este año" 
Señora de la Merced fue sustituida por la del Buen Ladrón, cambio que ya se había realizado en $1776^{36}$. ¿Qué motivó tal situación? Escribe el cronista Antonio Capmany y Montpalau (1742-1813), sin dar mejor información de sus fuentes, que la imagen de San Dimas procede de "un humilladero de este santo, perteneciente al duque de Monteleón, en donde se veneraba una imagen al natural del mismo y además sus santas reliquias... pero habiéndose secuestrado los bienes al duque, pidió la comunidad de la Merced Calzada la imagen y las reliquias, porque así lo tenia acordado que se hiziera caso de faltar la capilla. Se le concedió esto a la orden de la Merced, colocando la estatua y los restos preciosos de San Dimas, en un retablo frente al sepulcro de los nietos de Hernán Cortes ${ }^{37}$. Por lo tanto, tan destacado lugar, en plena capilla mayor y rodeado de santos mercedarios, no era gratuito y se le otorgaría por la vinculación de la imagen con los duques de Monteleón, descendientes directos de don Fernando y doña Mencía los patronos de la capilla Mayor. Recordemos que la sobrina nieta de ambos, Juana Tagliavia d'Aragona Carrillo de Mendoza, VI Marquesa del Valle, V duquesa de Terranova y adusta camarera de las dos esposas de Carlos II, casó con Hector Pignatelo, VI duque de Monteleón, naciendo de esta unión doña Juana d'Aragona Pignatelo y Cortés, quien acumuló para ella y sus descendientes, además del marquesado del Valle, los ducados de Terranova y Monteleón.

De ser así, tal donación debió de ser aceptada gustosamente por los mercedarios que desde el papado de Sixto V (1585-1590), disfrutaban, cada 24 de abril, de conmemoración propia, con rito doble, en honor al Buen Ladrón ${ }^{38}$, como bien recuerda el ya citado Interián de Ayala ${ }^{39}$, por lo que, unido a que en la donación también iban incluidas unas reliquias del Santo, era sin duda el relicario el lugar idóneo para ser colocarlas decorosamente. Por lo tanto, y a tenor de estos antecedentes no es extraño que el citado dibujo de Vicente López, respondiera a un intento por parte de la comunidad de difundir su devoción a través de una estampa grabada.

Ya en el sigloXIX si bien la imagen logró aguantar el primer envite que supusieron las frustradas medidas desamortizadoras del rey José I reunidas en el decreto del 6 de

36 PONZ. Antonio. Op. cit. p. 104.

37 CAPMANY Y MONTPALAU. Antonio. Origen histórico y etimológico de las calles de Madrid. Madrid, Imprenta de Manuel B. de Quirós, 1863. pp. 371-372.

38 Si bien, el Martyrologium Romanum del Cardenal Baronio (1583) fijó la fiesta del Buen Ladrón, el 25 de marzo (siguiendo una antigua tradición medieval que hacia coincidir la muerte de Jesucristo, y por tanto la de este, con la conmemoración de la Encarnación), con la concesión del 24 de abril se evitaba precisamente que esta quedara eclipsada. Sobre la liturgia seguida este día por la orden véase: MONTON. Joseph. Buen uso de el Breviario, theoria, y practica de las rubricas del Oficio divino segun el orden romano: Obra exornada con algunas Reflexiones Mysticas, Historicas, y Morales, que promueuen la devocion, para el buen uso de el Breviario. Zaragoza, Imprenta de Francisco Moreno, 1741. p. 151. y Ceremonial del coro y del altar, e instrucción de oficios de los religiosos descalzos de la Orden de Nuestra Señora de la Merced Redempcion de Cautivos. Madrid, imprenta de Francisco Xavier García, 1767. p. 59. A partir de este momento aquellas instituciones que obtuvieron de la Congregación de Ritos fiesta propia al Buen Ladrón, como Confesor no Pontífice, seguirían las normas y la fecha otorgadas a los Mercedarios. Así el caso, ya visto, de la ciudad de Valencia (1729), o el de la Congregación de los Piadosos Operarios (1724). Para este último, véase: MONTON. Joseph. Op. cit. p. 151. y más ampliado en: BENEDICTO XIV (Papa). Benedicti XIV. Pont. Op. Max. olim prosperi cardinali de Lambertinis Opera Omnia in unun corpus collecta. Veneti, typographia Bassanensi, Remondini. 1767. p. 334. 39 "particularmente rezando mi Religión del Santo Ladrón con rito doble el día 24 de Abril". INTERIAN DE AYALA. Juan. Op. cit. p. 171 
Agosto de 1809, siendo la única imagen recogida en el inventario levantado del convento el 23 de Agosto $^{40}$, no pudo contra la promulgada por el ministro Mendizábal veintiséis años después. Esta última fue progresiva, perfilándose gradualmente la definitiva Ley de 1837 mediante Reales decretos que se fueron sucediendo desde julio de 1835.

En 1835, una vez abandonado el convento por los mercedarios, la imagen es recogida de nuevo en el crucero, en el inventario levantado por la Real Academia de Bellas Artes de Fernando, siendo la única cuyo autor "Juan de Mena" aparece recogido junto a ella ${ }^{41}$. El 28 de mayo de 1836, aún no había sido trasladados los bienes del convento de la Merced al depósito de la Trinidad, futuro Museo Nacional| ${ }^{42}$, acción que se vio acelerada con el anuncio el 17 de febrero de 1837 de la demolición del convento para dejar paso a la Plaza del Progreso - hoy Tirso de Molina -, trabajo que le sería encomendado al contratista Jenaro Antonio Rubijo ${ }^{43}$. Esta, y otras obras de escultura de igual procedencia ${ }^{44}$, entre las que estaría la del El Buen Ladrón, quedaron allí almacenadas al parecer, hasta 1842.

Con la apertura provisional del Museo el 24 de julio de 1838, vuelve a aparecer en los inventarios una imagen de San Dimas, por ultima vez, recogida en una sala donde expusieron cincuenta y dos de las más significativas esculturas, según el criterio de la época, de la cantidad ingente de imaginería recogidas en él ${ }^{45}$. La inclusión de esta escultura en tan selecto grupo nos habla de la gran estimación de que gozó, ya no solo por su iconografía, singular donde las haya y única en Madrid, sino también por su estimable calidad e imponente presencia. Recordemos que junto a San Dimas se encontraban otras cumbres de la imaginería madrileña como el celebrado Cristo del Perdón del Convento del Rosario obra de Manuel Pereira ${ }^{46}$.

A partir de esta fecha se le pierde la pista en la documentación madrileña hasta que vuelve a aparecer en 1849 ya en Bailén, siempre y cuando consideremos que ambas imágenes son la misma, como todo parecer indicar. No Obstante, podemos

40 Archivo General de Simancas. (A.G.S.). Gracia y Justicia. Leg. 1247. citado por ANTIGÜEDAD DEL CASTILLO-OLIVARES. María Dolores. José Bonaparte y el patrimonio artístico de los conventos madrileños. Madrid, Editorial de la Universidad Complutense, 1987. pp.427-428.

41 Archivo de la Real Academia de Bellas Artes de San Fernando (A.R.A.B.A.S.F). Leg. 7-130-1 (9)

42 Sobre la historia del Museo Nacional de La Trinidad y sus colecciones, véase: GAYA NUÑO. Juan Antonio.

"El Museo de la Trinidad (Historia y catálogo de una pinacoteca desaparecida)", Boletín de la Sociedad Española de Excursiones. 1947. Tomo LI. pp.19-77; NAVARRETE PRIETO. Benito. "La creación del Museo de la Trinidad. Datos para su estudio", Boletín de la Real Academia de Bellas Artes de San Fernando. № 83 Segundo Semestre, 1996. pp. 507-526; ANTIGÜEDAD DEL CASTILLO OLIVARES. Ma Dolores. "EI Museo de la Trinidad, germen del museo publico en España". Espacio, Tiempo y Forma, № 11, Madrid, 1998, pp. 367-396; ÁlVAREZ LOPERA. José. El Museo de la Trinidad en el Prado. Madrid, Museo del Prado, 2004 y ÁLVAREZ LOPERA. José. El Museo de la Trinidad: historia, obras y documentos (1838-1872). Madrid , Museo del Prado, 2009

43 A.R.A.B.A.S.F. Leg. 7-129-1 (62) y (63). A cuenta de la propiedad de la puerta de acceso al Aula de Dibujo que la Academia gestionaba en el Convento de la Merced.

44 Que tengamos sus nombres documentados: Una Virgen de la Merced mayor que el natural (Seguramente la que presidía el retablo mayor citada por Ponz y Ceán como obra de Mena) y un San Ramón Nonato, se citan en la Sala de Esculturas del Museo como procedentes de la Merced en 1839. A.R.A.B.A.S.F. Leg. 1-55-2. Quizá se tenga que añadir otra de San Pedro Armengol, calificada como de merito (junto a las anteriores) en el inventario de 1836. A.R.A.B.A.S.F. 7-130-1 (9)

45 A.R.A.B.A.S.F. Leg. 1-55-2.

46 La imagen del Cristo del Perdón de Manuel Pereira ya estaba en el deposito de la Trinidad el 5 de marzo de 1836. A.R.A.B.A.S.F. Leg. 7-128-1 (56). 
suponer que tardaría aún en salir del Museo de la Trinidad. En concreto, en 1842 se vuelven a localizar las imágenes traídas de la Merced en el trascoro de la Iglesia y la sala contigua y si bien es cierto que no se identifica ninguna, se puede suponer que para estas fechas aun estuviera depositada allíi7.

Desconocemos en qué momento justo saldría la imagen de la Trinidad y se hace realmente difícil dar una respuesta satisfactoria a esta pregunta a tenor del caos que marcó su gestión a partir de 1841, coincidiendo con las transferencias del control del Museo desde la Academia de Bellas Artes al Estado. Se hablaba de carretas repletas de imágenes que salían sin ningún control, ventas cuasi fraudulentas o subastas poco transparentes de piezas ${ }^{48}$. A lo que cabría añadir el abandono de los objetos en el propio Museo, más sangrante aun si nos referimos a las "efigies de santos" 4 , que desaparecen prácticamente de la documentación. A día de hoy resulta asombroso que el Cristo Flagelado de Miguel Ángel Nacherino, hoy en Museo Lázaro Galdiano, fuera vendido como despojo al demolerse el edificio en 1897, veinticinco años después de que sus fondos hubieran sido transferidos al Museo del Prado ${ }^{50}$.

No obstante, y después de este leve inciso, podemos sugerir dos momentos donde pudo haber salido El Buen Ladrón con destino a Bailén o cualquier otro punto intermedio. El primero fue en 1842, durante la reapertura del Museo, donde una orden ministerial acordaba la distribución a las iglesias de Madrid o a la de cualquier pueblo que lo reclamase de la gran cantidad de retablos y esculturas que se almacenaban en el recinto. Si bien es cierto que en principio se intentó hacer de una manera ordenada (mediante la presentación de un recibo) con la apertura del Museo al público este sistema saltó por los aires, naufragando las entregas en un verdadero descontrol no quedando las salidas recogidas en ningún sitio ${ }^{51}$. Sin embargo, cabría la posibilidad, lamentablemente imposible de comprobar, de que la imagen de San Dimas aguantara estas medidas, ya que "en principio" estas iban a afectar a imágenes sin ningún mérito artístico almacenadas en la iglesia y los subterráneos, y recordemos que San Dimas había sido seleccionada precisamente por su calidad, no hacia ni cuatro años, parar ser expuesta en sus salas. El otro, ocurrió cuatro años más tarde, en 1846, con la instalación en el edificio de la Trinidad del Conservatorio de las Artes. Esta decisión obligó a desocupar precipitadamente toda la planta baja donde se encontraban las estatuas, repartiéndolas a aquellas iglesias, capillas u oratorios que las reclamasen para su culto. Otras, que se encontraban en el refectorio, fueron sacadas precipitadamente al patio donde terminaron perdiéndose para siempre ${ }^{52}$.

47 A.R.A.B.A.S.F. Leg. 7-130-3 (19)

48 FERNANDEZ PARDO. Francisco. Dispersión y destrucción del patrimonio artístico español. Desamortizaciones (1815-1868). Tomo II. Madrid, Fundación Universitaria Española, 2007. p. 299.

49 Nombre, entre genérico y despectivo, usado regularmente en la documentación consultada del Museo de la Trinidad, a la hora de referirse a piezas de imagínería.

50 TORMO. Elías. "Miscelánea de escultura del siglo XVII en Madrid", Boletín de la Sociedad Española de Excursiones. 1910. Tomo XVIII. pp.113-117.

51 Declaración de Joaquín de Iñigo. Expediente incoado por el Ministerio de Fomento, agosto de 1854, tras la salida de Javier de Quinto de la dirección del Museo Nacional. Archivo General de la Administración (A.G.A.), Sección educación y cultura, caja 31/6784 (24).

52 Declaración de José Gálvez. Expediente instruido por el Ministerio de Fomento, agosto de 1854 (A.G.A.), Sección educación y cultura, caja 31/6784 (11) 
No es de extrañar que entre tanto despropósito la imagen de San Dimas saliese del Museo sin dejar ni rastro hacia las manos del duque de Osuna, y de estas a Bailén, donde ya estaba en 1849. Por lo tanto, y de forma provisional, podríamos acotar la fecha de su llegada entre 1838, ultima vez que se cita en Madrid, y 1849 cuando ya queda registrada entre los bienes de la parroquia de Bailén.

El Condado de Bailén, perteneciente al estado nobiliario de Arcos, había pasado en 1834 a la casa de Osuna por fallecimiento de Doña Maria Josefa de Pimentel, la retratada por Goya junto a su esposo el IX duque de Osuna, y sus hijos en el delicioso cuadro de la familia del Duque de Osuna del Museo del Prado. Doña María Josefa, entre otros muchos títulos, ostentaba por derecho propio, el de XII condesa de Bailén ${ }^{53}$, siendo sus sucesores hasta 1849 sus nietos, Pedro de Alcántara TéllezGirón y Beaufort entre (1820-1844) y posteriormente el hermano de este, Mariano Téllez-Girón y Beaufort (1844-1882) el XII Duque de Osuna y XIV de Bailén. ¿A quién de los dos Duques se le debe la llegada de la imagen a Bailén? No lo sabemos con seguridad, aunque sí existen indicios que nos permitan inclinarnos hacia don Mariano, personaje espléndido y derrochador hasta el extremo ${ }^{54}$, que llegó a atesorar la mayor cantidad de títulos nobiliarios del momento, además de la mayor fortuna de España que terminó dilapidando, llevando a la Casa de Osuna a la más estrepitosa ruina ${ }^{55}$.

Según el citado inventario de La Encarnación de 1849 el encargado de entregar la imagen en la parroquia fue el administrador del duque en Bailén, Carlos Pasute ${ }^{56}$ (sic) personaje que, efectivamente, aparece en los empleados de la casa, pero como Passuti. Indagando en la documentación hemos podido comprobar que don Carlos, ejerció el cargo de administrador de Bailén bajo el mandato de don Mariano TéllezGirón, como consta en unas cartas escritas por él y remitidas al Duque en $1848^{57}$. Por lo tanto las fechas que hemos barajado con anterioridad sobre la posible salida de la imagen del Museo de la Trinidad, 1842 y 1846, coincidiendo esta última con la instalación en el edificio del Instituto de Artes, parecen coincidir, o cuanto menos, acercarse con la presencia de Pasutti en Bailén y por tanto de la llegada del San Dimas, que quizá se dio en el intervalo de 1847 a 1849 de la mano por tanto del XII Duque de Osuna. Recordemos que por estas fechas don Mariano, gran aficionado a las artes, disfrutaba de una perfecta sintonía con la Academia de la Historia, y con de Bellas Artes de San Fernando que le acababa de nombrar académico de honor en 1845, y que si bien se le había privado a esta institución del control del Museo, aún mantenía su parcela de poder. Cabría añadir a ello sus influencias en el campo de la política desde su cargo de

53 VALVERDE FRAIKIN. José. Títulos Nobiliarios Andaluces. Granada, Editorial Andalucía, 1991. pp. 57, 90 y 394.

54 Entre otras excentricidades, estando como embajador en Rusia, en una de sus cenas llamadas de las mil y una noches (donde se disfrutaba de la carísima sopa de sterlets, se consumían frutas exportadas desde América y se regalaban flores traídas en trenes especiales desde Valencia y Niza) terminó arrojando la vajilla de oro a las profundidades del Neva para asombro de todos, incluido en zar y la zarina. MARICHALAR. Antonio. Riesgo y ventura del duque de Osuna. Madrid, Palabra, 1998. pp. 205-206.

55 Para la quiebra de la Casa de Osuna, véase: ATIENZA HERNÁNDEZ. Ignacio. Aristocracia, poder y riqueza en la España Moderna: la casa de Osuna, siglos XV-XIX. Madrid, Siglo XXI de España, 1987. pp.366-383.

56 CABAZAN. Alfredo. Op. cit. 1927a. pp. 186-187. CABAZAN. Alfredo. Op. cit. 1927b. pp. 22-23.

57 Archivo Histórico Nacional (A.H.N). Nobleza, Osuna, CT.339, D.1 
senador (1845-1846) $)^{58}$, que le colocaron en una posición privilegiada para hacerse con alguna pieza del Museo en estos momentos de confusión.

Si bien es cierto que las limosnas y donaciones a las parroquias de sus señoríos era algo común y existía una partida en los presupuestos de la casa para estos menesteres ${ }^{59}$, también lo es, que por estas fechas y como si esto de los obsequios a las iglesias con las que tenia el Duque una especial vinculación fuera una dinámica del momento, encontramos otros presentes, como la custodia entregada en 1848 a la sacramental de San Pedro y San Andrés de Madrid $^{60}$, parroquia donde fue bautizado y en cuya feligresía se encontraba su residencia madrileña del Bosque.

\section{Conclusiones.}

La desamortización de Mendizábal, supuso la destrucción, y en el mejor de los casos, la dispersión de gran parte del patrimonio escultórico que hasta este momento guardaban los conventos madrileños. Así parece que sucedió con la imagen del Buen Ladrón que se la venia localizando, al menos desde 1776, en el Crucero del desaparecido Convento madrileño de la Merced Calzada, como obra de Juan Pascual de Mena. Llegada la exclaustración esta fue recogida por la Real Academia de Bellas Artes de San Fernando en el depósito de obras de arte que se había creado en el también suprimido Convento de la Trinidad, donde según parece llegó a figurar entre las piezas seleccionadas para la apertura del Museo en 1838.

Unos años más tarde (1849) aparece ya inventariada en la iglesia de la Encarnación de Bailén la imagen de San Dimas que hemos estudiado. Esta llegaría desde Madrid entre 1847 y 1849, de la mano del XII Duque de Osuna, y, según todos los indicios, bien pudo ser la misma que la documentada en Madrid escasos años antes. Para plantear tal hipótesis nos hemos basado en los datos que conocemos de esta imagen madrileña que, a nuestro juicio, coinciden plenamente con la talla de Bailén. Así, el estilo practicado por el escultor Juan Pascual de Mena, a quien se atribuyó la imagen, se ajusta al mostrado en la talla de Bailén; analogías en el tamaño, superior a lo habitual; su inusual iconografía glorificada en el panorama artístico español, o las similitudes con el dibujo del pintor Vicente López que hemos damos a conocer, nos han permitido considerar ambas imágenes como una sola y por tanto ampliar el ya extenso catálogo de obras conservadas de Pascual de Mena.

58 PEIRÓ MARTíN. Ignacio, y PASAMAR ALZURIA. Gonzalo. Diccionario Akal de historiadores españoles contemporáneos (1840-1980). Madrid, Ediciones Akal, 2002. p.612.

59 En 1861 en plena quiebra financiera del duque, aun se mantenía esta partida entre los gastos fijos de la casa. ATIENZA HERNÁNDEZ. Ignacio. Op. cit. pp.376-377.

60 Archivo Histórico de Protocolos de Madrid (A.H.P.M.) Protocolo 25680. Fol. 1823. 
